\title{
Predictive Factors of Effects of an Interdisciplinary Chronic Disease Prevention and Management Intervention in Primary Healthcare: A Correlational Analysis
}

\author{
Maxime Sasseville $^{1^{*}}$, Maud-Christine Chouinard ${ }^{2}$ and Martin Fortin ${ }^{3}$ \\ ${ }^{1}$ Département des sciences de la santé, Université de Sherbrooke, Québec, Canada \\ ${ }^{2}$ Département des sciences de la santé, Université du Québec à Chicoutimi, Québec, Canada \\ ${ }^{3}$ Département de médecine de famille et de médecine d'urgence, Université de Sherbrooke, Québec, Canada
}

*Corresponding author: Maxime Sasseville, Faculty, Département des sciences de la santé, Université de Sherbrooke, Québec, Canada, Fax: 418-541-7091; E-mail: maxime.sasseville@usherbrooke.ca

Received date: Feb 05, 2016; Accepted date: Feb 22, 2016; Published date: Feb 29, 2016

Copyright: @ 2016 Sasseville M, et al. This is an open-access article distributed under the terms of the Creative Commons Attribution License, which permits unrestricted use, distribution, and reproduction in any medium, provided the original author and source are credited.

\begin{abstract}
Background

The purpose of this research was to explore the predictive factors (patient-related and intervention-related) of effects of an interdisciplinary and patient-centered chronic disease prevention and management (CDPM) intervention in an adult population with chronic diseases seen in primary healthcare (PHC).

\section{Methods}

This work presents the secondary analysis of data from the PR1MaC project, a pragmatic randomized controlled trial of an intervention involving the integration of canadian CDPM services in PHC. The main outcomes were dichotomic substantive improvement in the eight domains of the Health Education Impact Questionnaire (heiQ) measured at baseline and three months. Included in the multivariate analysis were the independent variables related to patient characteristics: age, gender, education, family income, marital status, multimorbidity, having healthy eating habits at baseline, doing sufficient physical activity at baseline; and those related to the intervention: duration of intervention, number of health professionals involved, health professionals working in consensus and number of risk factors aimed by the intervention objectives.
\end{abstract}

\section{Results}

A group of 160 patients ( 84 male; mean age $52.7 \pm 11.5$ years) from the intervention arm was considered. Multivariate logistic regression analysis showed that being younger, being single and having a higher family income is associated with improvement in Emotional Wellbeing. Having healthy eating habits and a limited number of patient-fixed objectives is associated with improvement in the Constructive Attitudes and Approaches. Also, being younger, longer intervention duration and consensus of the professionals is associated with improvement in the Health Services Navigation. An increasing intervention duration is associated with improvement in the Positive and Active Engagement in Life. Finally, increasing number of professionals is associated with improvement in the Skills and Techniques Acquisition.

\section{Conclusion}

The results showed specific associations that could lead in improvements in CDPM delivery, contributing to the understanding of the complex mechanisms of chronic disease management and support.

Keywords: Chronic disease; Chronic disease prevention and management; Predictive factors; Logistic regression; Interdisciplinarity; Primary healthcare; Secondary analysis; Patient education intervention

\section{Abbreviations}

BMI: Body Mass Index; CCM: Chronic Care Model; CD: Chronic Disease; CI: Confidence Interval; CDPM: Chronic Disease Prevention And Management; COPD: Chronic Obstructive Pulmonary Disease;
DBMA: Disease Burden Morbidity Assessment; heiQ: Health Education Impact Questionnaire; MSSS: Ministère De La Santé Et Des Services Sociaux; OR: Odds Ratio; PHC: Primary Healthcare; SD: Standard Deviation

\section{Background}

Global mortality shifting towards a higher burden of chronic diseases (CD) has urged health organizations to adopt a change of scheme. The WHO estimates that by $2030,56 \%$ of the 67 million 
Citation: Sasseville M, Chouinard MC, Fortin M (2016) Predictive Factors of Effects of an Interdisciplinary Chronic Disease Prevention and Management Intervention in Primary Healthcare: A Correlational Analysis. J Comm Pub Health Nurs 2: 112. doi: $10.4172 / 2471-9846.1000112$

Page 2 of 7

deaths will be attributable to $\mathrm{CD}$, which will also negatively impact the social and economic burden of chronic diseases [1,2]. Even if CD are responsible for $42 \%$ of total healthcare costs, Canadian healthcare funding is still mainly allocated to traditional acute-care [3]. Effective preventive and disease management approaches including health education and self-management support could reduce significantly the burden of chronic diseases [4,5]

The link between $\mathrm{CD}$ and known risk factors such as physical inactivity, alcool and tobacco use and unhealthy eating habits makes it a preventable public health issue [6]. Evidence supports the use of patient education and self-management support as key components of programs to improve the overall health of patients with chronic diseases [7,8]. Further recommendations for chronic diseases prevention and management (CDPM) programs claim that innovative strategies need to be integrated into primary healthcare [9-11], multimorbidity-focused [12], coordinated by primary healthcare nurses [13], and focussed on interdisciplinary collaboration $\quad[11,14]$.

Despite evidence of positive outcomes of such programs [15], the variability in weight and type of evidence shown between studies leaves space for a better understanding of the characteristics that lead to improvement of participant health in CDPM programs [16,17]. Currently, there is a research gap in the understanding of outcome development mechanisms from CDPM interventions. Thus, the aim of this study is to explore the predictive factors of positive outcomes of an interdisciplinary CDPM intervention among adult patients presenting chronic conditions or their risk factors in PHC.

\section{Methods}

\section{Design}

This study presents the secondary analysis of a pragmatic randomized controlled trial that examined the effects of an interdisciplinary CDPM intervention integrated into PHC practices: the PR1MaC project [18]. The current analysis follows a predictive correlational design with the goal to highlight the predictive factors of success of this CDPM intervention.

\section{Intervention}

Based on a pragmatic and a patient-centered approach, CDPM services in the PR1MaC project were adapted to patient needs and integrated in PHC services with focus on self-management support, health education, motivational interviewing and interprofessionnal collaboration. The intervention lasted 3 months and involved at least three individual interviews with CDPM practitioners, consisting of nurse coordinators, physical activity therapists, nutritionists, respiratory therapists and smoking cessation specialists [18].

\section{Population}

Patients were recruited from eight primary healthcare practices in the Saguenay-Lac-St-Jean region (Québec, Canada) [18]. Participants between 18 and 75 years old presenting at least one CD (diabetes, asthma, COPD, cardiovascular diseases) or CD risk factor (physical inactivity, obesity, unhealthy eating habits, smoking, glucose intolerance, metabolic syndrome) were identified by their primary healthcare provider. Patients with cognitive impairment or no rehabilitation potential according to their provider were not eligible. Analyses focused on the intervention arm sample of the randomized trial only and sought to characterize improvement in the eight domains of the Health Education Impact Questionnaire (heiQ) measured at baseline and after three months.

\section{Power analysis}

Rule of thumb in logistic regression proposes that a sample of ten events per variable for each independent variable included in the regression model is adequate to attain sufficient statistical power $[19,20]$. The intervention arm of the project included 160 participants and twelve independent variables were retained [21].

\section{Dependent variables}

Main outcomes were substantive improvement in the eight domains of the Health Education Impact Questionnaire (heiQ) measured at baseline and at three months. The heiQ is a self-assessment questionnaire with forty questions divided into eight domains (Health Directed Behavior, Positive and Active Engagement in Life, Emotional Wellbeing, Self-Monitoring and Insight, Constructive Attitudes and Approaches, Skill and Technique Acquisition, Social Integration and Support, Health Services Navigation) (Cronbach alphas from 0.7 to 0.89 [22]). A translated French Canadian version of the heiQ was used in the PR1MaC study [23]. The outcome of the heiQ is a dichotomic indication of substantial improvement in a domain. The substantial improvement is a variance-adjusted reliable change of mean between $\mathrm{T} 0$ and $\mathrm{T} 1$ [24] and constitutes the dichotomous dependent variable. The percentage of people who showed an improvement in each domain is shown in Table 1. Definitions of each domain of the heiQ are available in the original developmental work of the instrument [22].

\begin{tabular}{|l|l|}
\hline Domain & People who improved (\%) \\
\hline Health-directed Behavior & 30.1 \\
\hline Positive and Active Engagement in Life & 22 \\
\hline Skill and Technique Acquisition & 36.1 \\
\hline Constructive Attitudes and Approaches & 38.1 \\
\hline Self-Monitoring and Insight & 12.4 \\
\hline Health Services Navigation & 30.7 \\
\hline Social Integration and Support & 18.9 \\
\hline Emotional Wellbeing & 27.3 \\
\hline
\end{tabular}

Table 1: Percentage of people who improved for each heiQ domain.

\section{Independent variables}

Following the methods suggested by Kleinbaum to identify predictive factors with logistic regression, the first step of the statistical analysis was to identify significant variables from the scientific literature [25]. A literature review was conducted to identify characteristics associated with the success of CDPM programs for patients affected by chronic diseases and/or their risk factors. MEDLINE, CINAHL, PsycINFO and ERIC databases were consulted. Articles retained were peer-reviewed, quantitative in design, written in English or French and published between 1980 and 2013. Evaluation of the quality of the papers and the identification of characteristics related to positive outcomes of interventions in CDPM reduced the selection to eleve papers. The characteristics retained were separated into two 
Citation: Sasseville M, Chouinard MC, Fortin M (2016) Predictive Factors of Effects of an Interdisciplinary Chronic Disease Prevention and Management Intervention in Primary Healthcare: A Correlational Analysis. J Comm Pub Health Nurs 2: 112. doi: $10.4172 / 2471-9846.1000112$

Page 3 of 7

groups, patient-related and intervention-related. The patient-related characteristics were: age [26-28], gender [28-30], marital status [31], education [28], multimorbidity [29,32,33], self-efficacy (SE) [31], doing sufficient physical activity at baseline [31]. The interventionrelatedcharacteristics were: intervention duration [33], number of professionals involved [28], professionals working in consensus [28] and number of risk factors aimed by the intervention objectives [34]. Highlighted variables were associated with the same variable or a proxy present in the PR1MaC project database (Table 2).

\begin{tabular}{|c|c|}
\hline Characteristic from the literature & Included independent variable (type) from the PR1MaC project database \\
\hline \multicolumn{2}{|l|}{ Associated with patients } \\
\hline Chronic disease $<2[29,32,33]$ & Disease burden morbidity assessment score (DBMA) (continuous) \\
\hline Young age [26-28] & Age (continuous) \\
\hline Gender [28-30] & Gender (dichotomous) \\
\hline Education [28] & Education AND Family income (continuous) \\
\hline Doing physical activity at baseline [31] & Sufficient physical activity (dichotomous) Healthy eating habits (dichotomous) \\
\hline Having social support [31] & Marital status (dichotomous) \\
\hline \multicolumn{2}{|l|}{ Associated with the intervention } \\
\hline Continuity of care [28] & Professionals focusing on the same risk factors (dichotomous) \\
\hline Interprofessional collaboration [28] & Number of professionals (continuous) \\
\hline Disease-specific intervention [34] & Number of risk factors aimed by patient objectives (continuous) \\
\hline Primary healthcare context [44] & Not relevant \\
\hline Longer intervention [33] & Length of the intervention in hours (continuous) \\
\hline
\end{tabular}

Table 2: Patient and intervention characteristics from the literature and associated variables from the PR1MaC project database.

The intervention-related characteristics were gathered with a chart audit in the eight primary healthcare clinics where the intervention took place. Patient variables retained were age, gender, education, family income, marital status, number of chronic diseases and associated burden (score from the Disease Burden Morbidity Assessment by self-report) [35], self-reported healthy eating habits (consumption of five or more protion of fruit and vegetables daily) at baseline and sufficient physical activity (20-30 min of exercise 4 times per week) at baseline. Intervention variables retained were: intervention duration, number of primary healthcare professionals involved, primary healthcare professionals working in consensus and number of risk factors. Details on the instruments used are available elsewhere [18] (Supplementary table).

\section{Data analysis}

Dichotomous variables were correlated with significant characteristics from the literature, multicollinearity was assessed and univariate analysis was done for results interpretation. The main analysis performed is a backward stepwise method of logistic regression using SPSS statistics for Mac OS version 20 [36]. A statistic adjustment was then applied to the p-value based on BenjaminiHachberg's method of assessing false discovery rate bias in multiple testing analysis [37].

\section{Ethical considerations}

The PR1MaC project received approval from the research ethics board of the Centre de santé et de services sociaux de Chicoutimi
(Project 2010-044). Informed consent was obtained from all participants.

\section{Results}

\section{Sample description}

A sample of 160 patients ( 84 male) referred by PHC providers was assigned to the intervention arm (mean age $52.7 \pm 11.5$ years); $87.3 \%$ had completed high school; $58.4 \%$ were employed, $19 \%$ were smokers, $98.5 \%$ presented two or more chronic conditions and $31 \%$ had healthy eating habits at baseline. At three months post- intervention, $75.3 \%$ of the participants had attained sufficient improvement in at least one domain. Detailed information about the sample can be found in Table 3.

\begin{tabular}{|l|l|}
\hline Age, years (mean \pm SD) & $52.7 \pm 11.6$ \\
\hline Gender & \\
\hline Male (\%) & 52.5 \\
\hline Family Income CAN\$ (\%) & \\
\hline$<20,000$ & 12 \\
\hline $20,000-29,999$ & 8.4 \\
\hline $30,000-39,999$ & 13.3 \\
\hline $40,000-49,999$ & 13.3 \\
\hline
\end{tabular}


Citation: Sasseville M, Chouinard MC, Fortin M (2016) Predictive Factors of Effects of an Interdisciplinary Chronic Disease Prevention and Management Intervention in Primary Healthcare: A Correlational Analysis. J Comm Pub Health Nurs 2: 112. doi: $10.4172 / 2471-9846.1000112$

Page 4 of 7

\begin{tabular}{|l|l|}
\hline$>50,000$ & 50.6 \\
\hline Education (\% Highest completed) & \\
\hline Incompleted high school & 12.7 \\
\hline Completed high school & 34.9 \\
\hline College & 28.9 \\
\hline University & 22.3 \\
\hline Employment & \\
\hline Employed (\%) & 58.4 \\
\hline Marital status & \\
\hline Married (\%) & 68.7 \\
\hline Number of chronic diseases (mean \pm SD) & \\
\hline Smokers (\%) & 19 \\
\hline Healthy eating habits at baseline ${ }^{1}(\%)$ & 31 \\
\hline Doing sufficient physical activity at baseline ${ }^{2}$ (\%) & 10 \\
\hline $\begin{array}{l}\text { Number of risk factors on which the patient wanted to work } \\
\text { (mean } \pm \text { SD) }\end{array}$ & $2.2 \pm 0.8$ \\
\hline
\end{tabular}

\begin{tabular}{|l|l|}
\hline $\begin{array}{l}\text { Number of professionals involved in the intervention (mean } \pm \\
\text { SD) }\end{array}$ & $2.6 \pm 0.7$ \\
\hline Length of the intervention (mean hours \pm SD) & $4.0 \pm 1.5$ \\
\hline
\end{tabular}

Table 3: Participant characteristics, SD: Standard deviation, 1: consumption of five or more portion of fruit and vegetables daily, 2 : 20-30 minutes of activity 3-4 times per week.

\section{Characteristics of the participants linked to positive effects}

Associations showed by the logistic regression analysis are presented in Table 4. Age showed an inverse relationship with improvement in the Health Services Navigation domain $(\mathrm{OR}=0.965 ; \mathrm{p}=0.031)$ and Emotional Wellbeing $(\mathrm{OR}=0.964 ; \mathrm{p}=0.037)$. Income $(\mathrm{OR}=0.261 ; \mathrm{p}$ $=0.022)$ and education $(\mathrm{OR}=0.655 ; \mathrm{p}=0.011)$ also showed an inverse relationship with improvement in the Emotional Wellbeing domain. Other sociodemographic variables such as gender and education were not associated in any domain. Healthy eating habits at baseline was associated with the Constructive Attitudes and Approaches domain $(\mathrm{OR}=2.268 ; \mathrm{p}=0.03)$. Other health-related variables such as DBMA and doing sufficient physical activity at baseline were not associated with improvement in the statistical models.

\begin{tabular}{|c|c|c|c|c|c|c|c|}
\hline \multirow{2}{*}{ Domain } & \multirow{2}{*}{$\begin{array}{r}\text { Significant } \\
\text { independent variable }\end{array}$} & \multicolumn{3}{|c|}{ Multivariate analysis } & \multirow{2}{*}{$\begin{array}{l}\text { Univariate } \\
\text { p-value }\end{array}$} & \multirow{2}{*}{$\begin{array}{l}\text { Multivariate } \\
\text { p-value }\end{array}$} & \multirow{2}{*}{$\begin{array}{l}\begin{array}{l}\text { Adjusted } \\
\text { multivariate }\end{array} \\
\text { p-value1 }\end{array}$} \\
\hline & & $\operatorname{Exp} B$ & Inferior & Superior & & & \\
\hline $\begin{array}{l}\text { Positive and Active } \\
\text { Engagement in Life }\end{array}$ & $\begin{array}{r}\text { Length of the } \\
\text { intervention in hours }\end{array}$ & 1.413 & 1.016 & 1.8 & 0.038 & 0.024 & 0.288 \\
\hline \multirow[b]{2}{*}{$\begin{array}{r}\text { Skill and Technique } \\
\text { Acquisition }\end{array}$} & Age & 0.97 & 0.939 & 1.001 & 0.027 & 0.055 & 0.33 \\
\hline & $\begin{array}{r}\text { Number of } \\
\text { professionals }\end{array}$ & 1.725 & 1.042 & 2.856 & 0.03 & 0.034 & 0.408 \\
\hline \multirow{2}{*}{$\begin{array}{r}\text { Constructive } \\
\text { Attitudes and } \\
\text { Approaches }\end{array}$} & Healthy eating habits & 0.441 & 0.203 & 0.959 & 0.099 & 0.039 & 0.234 \\
\hline & $\begin{array}{l}\text { Number of risk by } \\
\text { patient objectives }\end{array}$ & 0.557 & 0.357 & 0.867 & 0.009 & 0.01 & 0.12 \\
\hline \multirow{3}{*}{$\begin{array}{r}\text { Health Services } \\
\text { Navigation }\end{array}$} & Age & 0.965 & 0.934 & 0.997 & 0.078 & 0.031 & 0.372 \\
\hline & $\begin{array}{l}\text { Professionals focusing } \\
\text { on the same risk factors }\end{array}$ & 2.314 & 1.008 & 5.311 & 0.271 & 0.048 & 0.147 \\
\hline & $\begin{array}{r}\text { Length of the } \\
\text { intervention in hours }\end{array}$ & 1.334 & 1.024 & 1.737 & 0.076 & 0.032 & 0.192 \\
\hline \multirow{2}{*}{ Emotional Wellbeing } & Age & 0.964 & 0.931 & 0.998 & 0.085 & 0.037 & 0.111 \\
\hline & Marital status & 0.655 & 0.472 & 0.909 & 0.267 & 0.011 & 0.132 \\
\hline
\end{tabular}

Table 4: Univariate and multivariate logistic regression analysis to predict improvement in the heiQ domains, only significant predictive factors are shown, 1: Multivariate analysis was adjusted using the Benjamini \& Hochberg method [37].

\section{Characteristics of the intervention linked to positive effects}

All intervention-related variables were associated with an improvement in at least one domain each. Longer intervention was associated with the Positive and Active Engagement in Life domain $(\mathrm{OR}=1.413 ; \mathrm{p}=0.024)$ and the Health Services Navigation domain $(\mathrm{OR}=1.334 ; \mathrm{p}=0.032)$. A limited number of risk factors on which the patient wanted to work was associated with improvement in the Constructive Attitudes and Approaches domain (OR $=0.557 ; \mathrm{p}=$ 0.01). Also, more professionals involved in the intervention showed improvement in the Skill and Technique Acquisition domain $(\mathrm{OR}=$ $1.725 ; \mathrm{p}=0.044)$. Having more professionals involved in the intervention is not sufficient; results showed that providers working 
Citation: Sasseville M, Chouinard MC, Fortin M (2016) Predictive Factors of Effects of an Interdisciplinary Chronic Disease Prevention and Management Intervention in Primary Healthcare: A Correlational Analysis. J Comm Pub Health Nurs 2: 112. doi: $10.4172 / 2471-9846.1000112$

Page 5 of 7

together on the same risk factors was associated with improvement in the Health Services Navigation domain $(\mathrm{OR}=2.314 ; \mathrm{p}=0.032)$.

\section{Multiple testing adjustment of Benjamini-Hochberg}

The increasing number of hypotheses in a statistic analysis is associated with a probability to find rare events, which could lead researchers to reject the null hypothesis and cause a type I error [38]. Benjamini and Hochberg (1995) developed an approach to control the false discovery rate in multiple statistical testing. This approach was preferred over the widely used Bonferroni approach for its increased power. When a statistical adjustment was applied to the results, we failed to reject the null hypothesis for all variables [25]. The impact of the adjustment on result interpretation will be discussed in the next section.

\section{Discussion}

Although associations were found in some aspects of the intervention, most known predictive factors from the literature did not attain the significance level in the regression models. In some domains, the dataset of the PR1MaC project offered a limited number of subjects who had improved, which could have reduced the likelihood of identifying associations in the Health Directed Behavior, SelfMonitoring and Insight and the Social Integration and Support domains.

Some sociodemographic variables and the number of chronic diseases (Disease Burden Morbidity Assessment score), offered little to no predictability of improvement in outcomes. The population studied presented a high percentage of multimorbidity with $83.8 \%$ of the participants having three chronic conditions or more. The high proportion of people with complex health conditions may have reduced the possibility to identify an association between the number of chronic diseases and improvement in the heiQ domains. Nevertheless, age offered prediction of a significant improvement for Health Services Navigation and Emotional Wellbeing, showing that older patients tended to get the least improvement from the intervention, results similar to previous observations [26,28,32,39]. Even if a multivariate association was found with age, univariate analysis did not show statistical significance in any domain, indicating possibility of noise or variable interaction. In contrast with other studies [28,30], gender was not identified as a predictive factor of effect. However, these studies identified contradictory associations, one showing a female gender association and another, a male gender association, indicating that it may be an inconsistent predictive factor.

Having healthy eating habits at baseline showed to be a predictive factor of improvement in the Constructive Attitude and Approaches domain. One study identified a relation with high level of physical activity [31], which we were unable to identify in our analysis, possibly due to a limited proportion of participants doing sufficient physical activity at baseline (10\%). Nevertheless, this analysis shows that healthy eating habits can be related to an improvement in the construction of attitudes as an indication of patients that want to take control over their life.

Being married showed an inverse relationship with the Psychological Well-Being domain in the population studied. These findings go against current evidence on the subject, which describes an association between happiness and being married [40]. Authors insist that controlling for satisfaction with marriage (self-assessed good or poo satisfaction with marriage situation) has an important effect on the self-assessed depression and well-being outcome variables, implying that people unhappy with their marriage have a lower happiness level then unmarried people [41]. Because the PR1MaC study did not include the measurement of satisfaction with marital situation, we are unable to control for that factor.

Family income also showed an inverse relationship with improvement in emotional well-being; this result could arise from the high economic status of our sample. Fifty-one percent of the sample identified their family income to be 50000 CAN\$ /year or more (scale maximum); this may position toward a restrained predictability of this independent variable because we had limited distribution in other categories. Also, family size was not assessed, therefore it was impossible to adjustfamily income for the family size. It is important to consider that in this domain, the results of the univariate and multivariate analysis do not match, indicating the potential presence of noise or interaction.

Longer interaction with the primary healthcare professionals showed a moderate to strong association with the Positive and Active Engagement in Life domain. This finding follows the assumption that increased exposure to the intervention would induce patient motivation to change their health habits. A longer contact with the healthcare team has also shown to be a predictive factor of improvement in the Health Services Navigation domain showing that it may help patients understand how the healthcare system works and how to communicate their care needs to the provider. Our results go in the same sense as Harrison et al. who demonstrated that a longer intervention was a predictive factor of program satisfaction in the population studied [26].

Another interesting finding was the association of number of professionals working with the patient and improvement in the Skill and Technique Acquisition domain. A multidisciplinary team is already described as a key element of efficient CDPM interventions [11]. Our findings revealed an improvement in the Skill and Technique Acquisition over the course of the program when more professionals were involved. Having more specialised healthcare providers engaged in a CDPM intervention leads to better knowledge-based skill and technique acquisition and a more efficient management of their symptoms. This result offers a better understanding of a key element of innovation in CDPM, the multidisciplinary intervention. Moreover, results showed that professionals working in a cohesive manner on the same risk factors was associated with improvement in the Health Services Navigation domain. As identified by other authors, disorganized and fragmented services constituted barriers for patients, such as confusion and feelings of being overwhelmed by the process [42]. Findings emphasize the importance of cohesive multidisciplinary teams in CDPM, showing that professionals working together offer coordinated care with direct improvement in the way patients perceive the healthcare delivery system and in communication of their needs to the provider.

A limited number of risk factors on which patients wanted to work showed to be associated with improvement in the Constructive Attitudes and Approaches domain. This indicates that a focused intervention can place patients in a situation where they want to take control over their health status. A literature review has already shown that interventions in the context of multimorbidity tend to be more successful when targeting one risk factor at a time [34].

Finally, it is important to assess the nature of the adjustments applied to the analysis. Numerous independent variables showed 
Citation: Sasseville M, Chouinard MC, Fortin M (2016) Predictive Factors of Effects of an Interdisciplinary Chronic Disease Prevention and Management Intervention in Primary Healthcare: A Correlational Analysis. J Comm Pub Health Nurs 2: 112. doi: $10.4172 / 2471-9846.1000112$

Page 6 of 7

significance in the models proposed. With the adjustment approach applied, we failed to reject the null hypothesis for all variables. This suggests that all results from the multivariate analysis could be false positives. Even if there is some criticism over the need for adjustment in multiple testing methods [43], it needs to be considered to make informed decisions about the results of the present study. Loss of significance after these statistical adjustments suggests that observations should be validated, but they open the door to the interpretation of results mechanisms in CDPM interventions [37].

\section{Limits and biases}

The intervention arm was limited to 160 participants and analysis showed that in some domains a relatively small portion of these participants improved. This limitation emphasizes the possible lack of power, providing some explanation as to why we were unable to highlight predictive factors in the Health Directed Behavior, SelfMonitoring and Insight and the Social Integration and Support domains. Thus, the limited power in some domains indicates that associations found in the study are likely to be an underestimation for the regression model used. Nonetheless, a more extensive sample could highlight other predictive factors for the variables that had a limited number of events.

The short post-intervention evaluation time ( 3 months) limits the spectrum of results that could be presented. Authors state that results at six months represent only short-term effects, therefore, our results could be complemented by the evaluation of effects over a longer term [16]. Even if the psychometric qualities of the heiQ are well established [22], it is still a fairly new tool that has been used in a limited number of published evaluation studiesusing it as an outcome measure, therefore it is difficult to compare our results with other studies. Also, the French-canadian version could also have introduced biases in the results.

\section{Conclusions}

This attempt at the identification of predictive factors of improvement offers only a glimpse of the complexity of the underlying mechanisms of CDPM interventions. In this analysis, an association with age is showed in the Health Services Navigation and Emotional Well-Being domains, identifying age as an important factor for intervention adjustment. The results showed that involving more professionals, having longer contact with the provider and providers working together were predictors of improvement for the patients. Additionally, a focused intervention including fewer risk factors seems to indicate improvement for the patient with $\mathrm{CD}$. From a clinical point of view, these findings offer characteristics of interest in modelling strategies for intervention implementation and effects evaluation. The small portion of variance explained indicates that there is a need for further investigation of the underlying process of improvement. Additionally, the impact of adjustments in a multivariate analysis is showed in this research and the high potential for false discovery highlights the need for validation before using these findings. In an attempt to describe causal relationships between relevant characteristics and improvement, this research adds to the understanding of the complex mechanisms of efficiency and provides information on the optimisation of CDPM delivery.

\section{Competing Interests}

The authors declare that they have no competing interests.

\section{Author Contributions}

MS conceived and designed the study and wrote the paper. MF and MCC supervised the project as supervisors of MS, graduate student in clinical sciences. All authors gave their final approval of the version of the manuscript submitted for publication.

\section{Acknowledgement}

MS is supported by the medical research centre of Universite de Sherbrooke. Martin Fortin is holder of the CIHR Applied Research Chair - Health Services and Policy Research on Chronic Diseases in Primary Care - CIHR-IHSPR / CHSRF / CSSSC. The PR1MaC study was peer-reviewed by the Fonds de Recherche en Santé du Québe (FRSQ) and funded by the Pfizer-FRSQ-MSSS Chronic Disease Fund. We would like to acknowledge the extended research team members for their contribution in the conception of the study. Furthermore we want to thank the partners from the Saguenay Lac-St-Jean health and social services agency, from the participating CSSS and PH clinics and from the community partners. We would like to thank Susie Bernier for he work in editing the manuscript.

\section{References}

1. World Health Organization (2008) World health statistics 2008. World Health Organization.

2. Chronic diseases and health promotion (2005) Preparing a health care workforce for the 21st century: the challenge of chronic conditions. World Health Organization.

3. Mirolla M (2004) The cost of chronic disease in Canada. GPI Atlantic.

4. Wagner EH, Austin BT, Von Korff M (1996) Organizing care for patients with chronic illness. Milbank Q 74: 511-544.

5. Dubé F, Noreau É, Landry G (2012) Cadre de référence pour la prévention et lagestion des maladies chroniques physiques en première ligne. Ministère de la Santé et des Services Sociaux.

6. Ezzati M, Lopez AD, Rodgers A, Vander Hoorn S, Murray CJ (2002) Comparative Risk Assessment Collaborating Group Selected major risk factors and global and regional burden of disease. Lancet 360: 1347-1360.

7. Bayliss EA, Ellis JL, Steiner JF (2007) Barriers to self-management and quality-of-life outcomes in seniors with multimorbidities. Ann Fam Med 5: 395-40.

8. Health Council of Canada (2012) Self-management support for Canadians with chronic health conditions: a focus for primary health care.

9. Clair M (2000) Les solutions émergentes. Commision d'étude sur les services de santé et les services sociaux. Gouvernement du Quebec: Quebec.

10. Schmittdiel JA, Shortell SM, Rundall TG, Bodenheimer T, Selby JV (2006) Effect of primary health care orientation on chronic care management. Ann Fam Med 4: 117-123.

11. Wagner EH (1998) Chronic disease management: what will it take to improve care for chronic illness? Eff Clin Pract 1: 2-4.

12. Goetzel RZ, Ozminkowski RJ, Villagra VG, Duffy J (2005) Return on investment in disease management: a review. Health Care Financ Rev 26: 1-19.

13. Health Care System (2007) Primary Health Transition Fund: Summary of Initiatives: Final Edition. Health Canada.

14. Bodenheimer T, Lorig K, Holman H, Grumbach K (2002) Patient selfmanagement of chronic disease in primary care. JAMA 288: 2469-2475.

15. Tsai AC, Morton SC, Mangione CM, Keeler EB (2005) A meta-analysis of interventions to improve care for chronic illnesses. Am J Manag Care 11: 478-488.

16. Cooper H, Booth K, Fear S, Gill G (2001) Chronic disease patient education: lessons from meta-analyses. Patient Educ Couns 44: 107-117. 
Citation: Sasseville M, Chouinard MC, Fortin M (2016) Predictive Factors of Effects of an Interdisciplinary Chronic Disease Prevention and Management Intervention in Primary Healthcare: A Correlational Analysis. J Comm Pub Health Nurs 2: 112. doi: $10.4172 / 2471-9846.1000112$

Page 7 of 7

17. Coster S, Norman I (2009) Cochrane reviews of educational and selfmanagement interventions to guide nursing practice: a review. Int J Nurs Stud 46: 508-528.

18. Fortin M, Chouinard MC, Bouhali T, Dubois MF, Gagnon C, et al. (2013) Evaluating the integration of chronic disease prevention and management services into primary health care. BMC Health Serv Res 13: 132.

19. Peduzzi P, Concato J, Feinstein AR, Holford TR (1995) Importance of events per independent variable in proportional hazards regression analysis. II. Accuracy and precision of regression estimates. J Clin Epidemiol 48: 1503-1510.

20. Polit DF (2010) Statistics and Data Analysis for Nursing Research. (2ndedn), Boston: Pearson: Prentice Hall.

21. Vittinghoff E, McCulloch CE (2007) Relaxing the rule of ten events per variable in logistic and Cox regression. Am J Epidemiol 165: 710-718.

22. Osborne RH, Elsworth GR, Whitfield K (2007) The Health Education Impact Questionnaire (heiQ): an outcomes and evaluation measure for patient education and self-management interventions for people with chronic conditions. Patient Educ Couns 66: 192-201.

23. Bélanger A, Hudon C, Fortin M, Amirall J, Bouhali T, et al. (2004) Validation of a French-language version of the health education impact Questionnaire (heiQ) among chronic disease patients seen in primary care. Health Qual Life Outcomes.

24. Maassen GH (2004) The standard error in the Jacobson and Truax Reliable Change Index: the classical approach to the assessment of reliable change. J Int Neuropsychol Soc 10: 888-893.

25. Kleinbaum, David G, Klein, Mitchel (2010) Logistic regression: a selflearning text. New York: Springer New York.

26. Harrison M, Fullwood C, Bower P, Kennedy A, Rogers A, et al. (2011) Exploring the mechanisms of change in the chronic disease selfmanagement programme: secondary analysis of data from a randomised controlled trial. Patient Educ Couns 85: e39-47.

27. Packer TL, Boldy D, Ghahari S, Melling L, Parsons R, et al. (2012) Selfmanagement programs conducted within a practice setting: who participates, who benefits and what can be learned? Patient Educ Couns 87: 93-100.

28. Houle J, Beaulieu MD, Lussier MT, Del Grande C, Pellerin JP, et al. (2012) Patients' experience of chronic illness care in a network of teaching settings. Can Fam Physician 58: 1366-1373.

29. Bowden DE, Barr N, Rickert S (2012) An evaluation of the effects of chronic diseases and health conditions on tobacco cessation. Health Education Journal 71: 309-319.

30. Kirk JK, Davis SW, Hildebrandt CA, Strachan EN, Peechara ML, et al. (2011) Characteristics associated with glycemic control among family medicine patients with type 2 diabetes. N C Med J 72: 345-350.
31. Bonsaksen T, Lerdal A, Fagermoen MS (2012) Factors associated with self-efficacy in persons with chronic illness. Scand J Psychol 53: 333-339.

32. Dorr DA, Wilcox AB, Brunker CP, Burdon RE, Donnelly SM (2008) The effect of technology-supported, multidisease care management on the mortality and hospitalization of seniors. J Am Geriatr Soc 56: 2195-2202.

33. Harrison M, Reeves D, Harkness E, Valderas J, Kennedy A, et al. (2012) A secondary analysis of the moderating effects of depression and multimorbidity on the effectiveness of a chronic disease self-management programme. Patient Educ Couns 87: 67-73.

34. Smith SM, Soubhi H, Fortin M, Hudon C, O'Dowd T (2012) Managing patients with multimorbidity: systematic review of interventions in primary care and community settings. BMJ 345: e5205.

35. Bayliss EA, Ellis JL, Steiner JF (2005) Subjective assessments of comorbidity correlate with quality of life health outcomes: initial validation of a comorbidity assessment instrument. Health Qual Life Outcomes 3: 51 .

36. IBM C (2011) IBM SPSS Statistics for Macintosh. IBM Corp: Armonk.

37. Benjamini Y, Hochberg Y (1995) Controlling the false discovery rate: a practical and powerful approach to multiple testing. Journal of the Royal Statistical Society, pp. 289-300.

38. Watkins MP, Portney LG (2009) Foundations of clinical research: applications to practice. Pearson/Prentice Hall.

39. Reeves D, Kennedy A, Fullwood C, Bower P, Gardner C, et al. (2008) Predicting who will benefit from an Expert Patients Programme selfmanagement course. Br J Gen Pract 58: 198-203.

40. Kiecolt-Glaser JK, Newton TL (2001) Marriage and health: his and hers. Psychol Bull 127: 472-503.

41. Chapman B, Guven C (2010) Marital Status is misunderstood in happiness models, in Economics series. Deakin University, Faculty of Business and Law, School of Accounting, Economics and Finance.

42. Maneze D, Dennis S, Chen HY, Taggart J, Vagholkar S, et al. (2014) Multidisciplinary care: experience of patients with complex needs. Aust J Prim Health 20: 20-26.

43. Rothman KJ (1990) No adjustments are needed for multiple comparisons. Epidemiology 1: 43-46.

44. Taggart J, Williams A, Dennis S, Newall A, Shortus T, et al. (2012) A systematic review of interventions in primary care to improve health literacy for chronic disease behavioral risk factors. BMC Fam Pract 13: 49. 